\title{
TROPICAL BOUNDARY LAYER EQUILIBRIUM IN THE LAST ICE AGE
}

\author{
Alan K. Betts \\ Atmospheric Research, Middlebury, Vermont \\ W. Ridgway \\ Applied Research Corporation, Landover, Maryland
}

\begin{abstract}
A radiative-convective boundary layer model is used to assess the effect of changing sea surface temperature, pressure, wind speed, and the energy export from the tropics on the boundary layer equilibrium equivalent potential temperature. It remains difficult to reconcile the observations that during the last glacial maximum $(18,000 \mathrm{yr}$ BP) the snowline on the tropical mountains fell $950 \mathrm{~m}$, while the tropical sea surface temperatures fell only 1-2 K.
\end{abstract}

\section{Introduction}

The tropical climate during the last glacial maximum $(18,000 \mathrm{yr}$ B.P.) raises many fascinating questions. Here we shall try to reconstruct, from a few key observations, plausible conditions for the tropical oceanic boundary layer, using the simple one-dimensional model of Betts and Ridgway [1989], abbreviated BR89. It is believed that tropical sea surface temperatures (SST) were at the most $2 \mathrm{~K}$ lower than at present, the best estimate being only $1.4 \mathrm{~K}$ lower [Climate: Long-Range Investigation, Mapping, and Prediction (CLIMAP), 1981]. These small falls of SST in the tropics are in apparent conflict with the large falls in the snowline on the tropical mountains for which the best estimate is $950 \pm 50 \mathrm{~m}$ [see Rind and Peteet, 1985]. For the same epoch the fall of sea level in the tropics due to the accumulation of water in the high-latitude ice sheets was about $120 \mathrm{~m}$, and atmospheric $\mathrm{CO}_{2}$ was about $195 \mathrm{ppm}$, [Rind, 1987], in comparison with its present value of 330 ppm.

\subsection{Discussion}

The fall of sea level is consistent with the large redistribution in water from the oceans to the ice sheets. It implies a long period of enhanced evaporation from the warm tropical ocean's poleward advection and precipitation as snow on the continents. The evaporation of $120 \mathrm{~m}$ of water corresponds to a surface latent heat flux of $10 \mathrm{~W} \mathrm{~m}^{-2}$ for 1000 years! This is small, but it may be a significant perturbation of the tropical energy budget (see below). This fall of sea level will produce an increase in the pressure at the new lower sea surface because the redistribution of water

\section{Copyright 1992 by the American Geophysical Union.}

Paper number 91JD02974.

0148-0227/92/91JD-02974\$05.00 from the oceans to the continental ice sheets produces a corresponding reverse displacement of air. The first approximation, the pressure at the current sea level, is however unchanged because the mass of air displaced by the ice approximately equals the mass of air which replaces the evaporated seawater. (There are small corrections: water expands about $10 \%$ on freezing, but this is offset by the fact that the density of air changes a similar amount between sea level and the pressure and temperature on the continental ice sheets.)

The fall of the snowline on the tropical mountains has led to extensive debate during the last few years [ Rind and Peteet, 1985; Broecker, 1989; Rind, 1990]. The fall of snowline is too large to be explained by the small fall of SSTs in the tropics [Rind and Peteet, 1985]. However, the height of the freezing level does not depend simply on SST. It depends on the thermal structure above the surface in the lower troposphere. The vertical structure of the present tropical atmosphere is controlled by a balance of radiative and convective processes. The warm SSTs are maintained primarily by a balance of the incoming solar radiation and the surface evaporation. An unstable vertical structure is maintained by a comparable net longwave cooling of the atmosphere. The atmospheric thermal balance is maintained when the water vapor evaporated at the surface is condensed and precipitated out from deep convective systems. The convective response to destabilization is so fast that the resulting vertical structure in the tropics is always very close to a moist equilibrium structure and a little unstable with respect to the wet adiabatic lapse rate in the lower troposphere [Riehl, 1979; Betts, 1982; Xu and Emanuel, 1989]. Air ascends into cumulonimbus clouds from a moist subcloud layer, reaching saturation at cloud base about 60 mbar above the surface. The moist adiabat is the thermodynamic path followed by such a saturated air parcel as it ascends adiabatically with condensation. Each wet adiabat is conventionally labeled by $\theta_{\mathrm{B}}$, the equivalent potential temperature, which is the maximum potential temperature reached by the parcel as it ascends to the upper troposphere and condenses out all its water vapor. The equilibrium value of $\theta_{\mathrm{E}}$ near the surface over the oceans thus determines the moist adiabatic ascent path and the equilibrium vertical thermal structure of the tropics. We have no reason to believe on either theoretical grounds or from climate model simulations [Rind, 1987] that this tight convective coupling between $\theta_{\mathrm{E}}$ and atmospheric structure would be any different over the warm oceans in the glacial period. On a given $\theta_{\mathrm{E}}$ wet adiabat, the freezing level (which we can expect to be associated closely with the snowline) is at a fixed pressure, so that the height of the snowline (above 
the present sea level) is essentially constant unless $\theta_{\mathrm{E}}$ changes. Thus a drop of the snowline of $950 \mathrm{~m}$ requires a large drop of $\theta_{\mathrm{B}}(\approx 14 \mathrm{~K}$, see below) in the low-level air over the tropical oceans, so that the whole troposphere shifts to a cooler temperature. The low-level $\theta_{\mathrm{E}}$ is in turn a function of low-level pressure, temperature, and humidity.

Figure 1 summarizes the physical processes and the simplified moist thermodynamics associated with convection in the tropics on a pressure-temperature diagram. Air from the subcloud layer rises with condensation in cumulonimbus clouds to reach thermal equilibrium below the tropical tropopause (the schematic on the left). A horizontal line marks the current freezing level in the midtroposphere. Temperature, humidity, and pressure in the subcloud layer determine cloud base and the ascent wet adiabat. Below cloud base, the fall of temperature with height is the dry adiabatic lapse rate of $-9.7 \mathrm{~K} \mathrm{~km}^{-1}$. The sloping dry adiabats in the subcloud layer are lines of constant potential temperature, $\theta$. Above cloud base, the moist adiabatic lapse rate is less, about $-5 \mathrm{~K} \mathrm{~km}^{-1}$. As cloud air ascends from cloud base to the upper troposphere, it is warmed by condensation from a dry potential temperature of $\theta$ to the value $\theta_{\mathrm{B}}$, indicated by the dotted line. This is the definition of the equivalent potential temperature of a parcel. For a parcel in the subcloud layer this asymptotic value of $\theta_{\mathrm{E}}$ is given by [Betts, 1982]

$$
\theta_{\mathrm{E}}=\theta \exp \left(2.67 \mathrm{q} / \mathrm{T}^{*}\right)
$$

where $\theta$ is potential temperature, $q$ is mixing ratio, and $T^{*}$ is temperature at the lifting condensation level (cloud base).

As the ascent wet adiabat falls to lower values of $\theta_{\mathrm{E}}$ and the atmosphere gets coolet, the height of the freezing level $\left(0^{\circ} \mathrm{C}\right.$ level) also falls, as shown. This is discussed in section 1.2. There are three ways to produce a drop in subcloud layer $\theta_{\mathrm{g}}$ : a drop of temperature $\left(\Delta \mathrm{T}_{0}\right)$, a fall of moisture $\left(\Delta \mathrm{q}_{0}\right)$, or an increase of surface pressure $\left(\Delta \mathrm{p}_{\mathrm{o}}\right)$. The coupling between the low level air temperature and moisture and the SST, surface pressure, and wind are discussed in section 2.

\subsection{Relationship of Low- Level $\theta_{\mathrm{p}}$ to \\ Height of Freezing Level}

For the wet adiabatic atmosphere shown in Figure 1, it is straightforward to compute the drop of freezing level with $\theta_{\mathrm{g}}$. This is shown in Figure 2 as a dashed line. We have taken the present-day equilibrium value of $\theta_{\mathrm{E}}$ as 346.9 $K$, corresponding to the boundary layer equilibrium solution by BR89 over an SST of $300 \mathrm{~K}$, with a surface pressure of $1012 \mathrm{mbar}$ and a surface wind speed of $6.7 \mathrm{~m} \mathrm{~s}^{-1}$. The wet adiabat is the simplest reference structure. However, there is evidence that below the freezing level, the tropical atmosphere is more unstable and closer to a second reference: the wet virtual adiabat [Betts, 1982, 1985; Xu and Emanuel, 1989; Betts and Bartlo, 1991]. This wet virtual adiabat is the neutral density adiabat for reversible moist ascent where liquid water loading is considered. The solid line in Figure 2 shows the dependence of the fall of the freezing level on the wet virtual adiabat through a given $\theta_{\mathrm{E}}$ at a cloud base height of 950 mbar. For the wet adiabatic reference atmosphere (dashed line) the freezing level corresponding to the zero line for $\theta_{\mathrm{E}}=346.9 \mathrm{~K}$ is $5114 \mathrm{~m}$, while for the cooler wet virtual adiabatic atmosphere (solid line) the zero line corresponds to $4685 \mathrm{~m}$. The present snowline values are in between, around $4800 \mathrm{~m}$. A drop of $950 \pm 50 \mathrm{~m}$ in freezing level $\left(z_{p}\right)$ then corresponds to a fall of $\theta_{\mathrm{E}}$ to $333.7 \pm 0.7 \mathrm{~K}$, if the tropical atmosphere has a wet adiabatic structure (dashed line), and $332.1 \pm 0.7 \mathrm{~K}$, if the tropical atmosphere

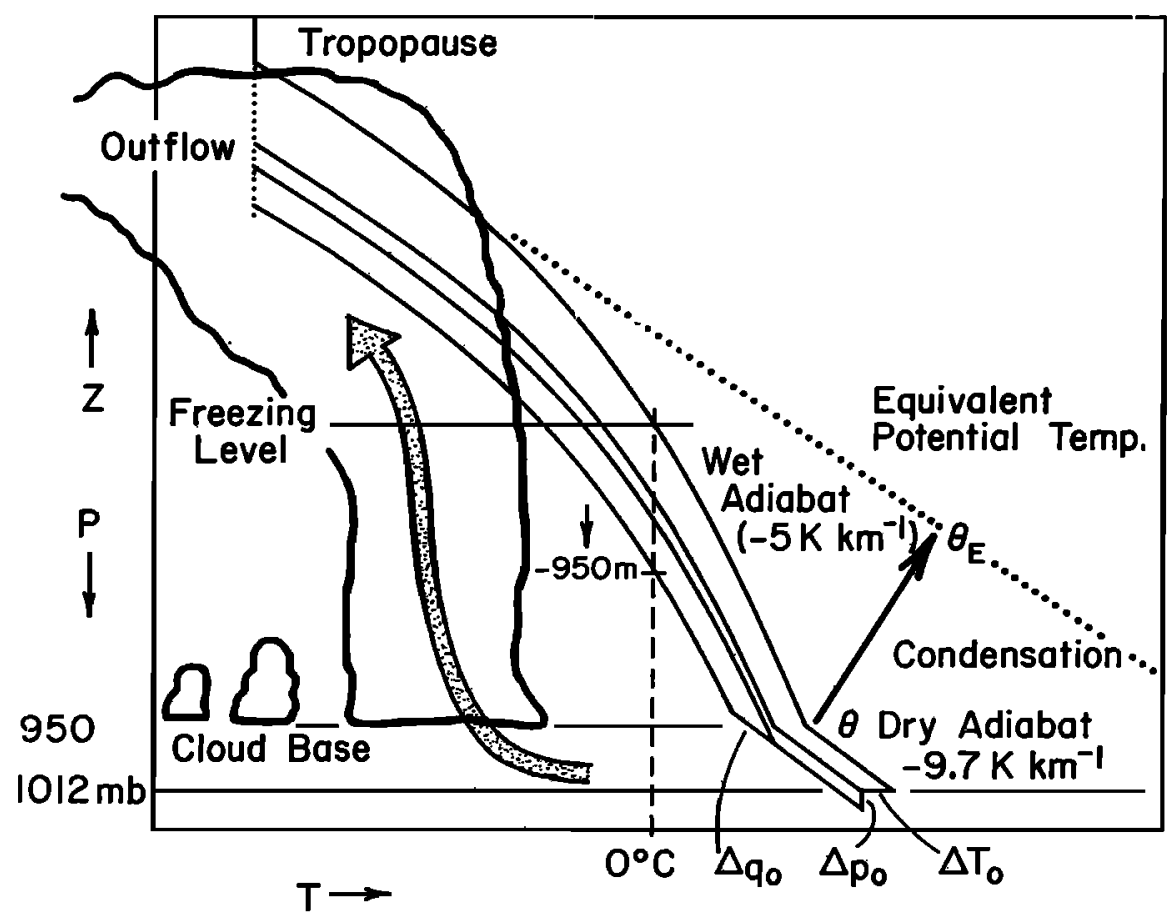

Fig. 1. Schematic showing the dependence of the wet adiabat and freezing level on changes in near-surface air temperature, pressure, and humidity. 


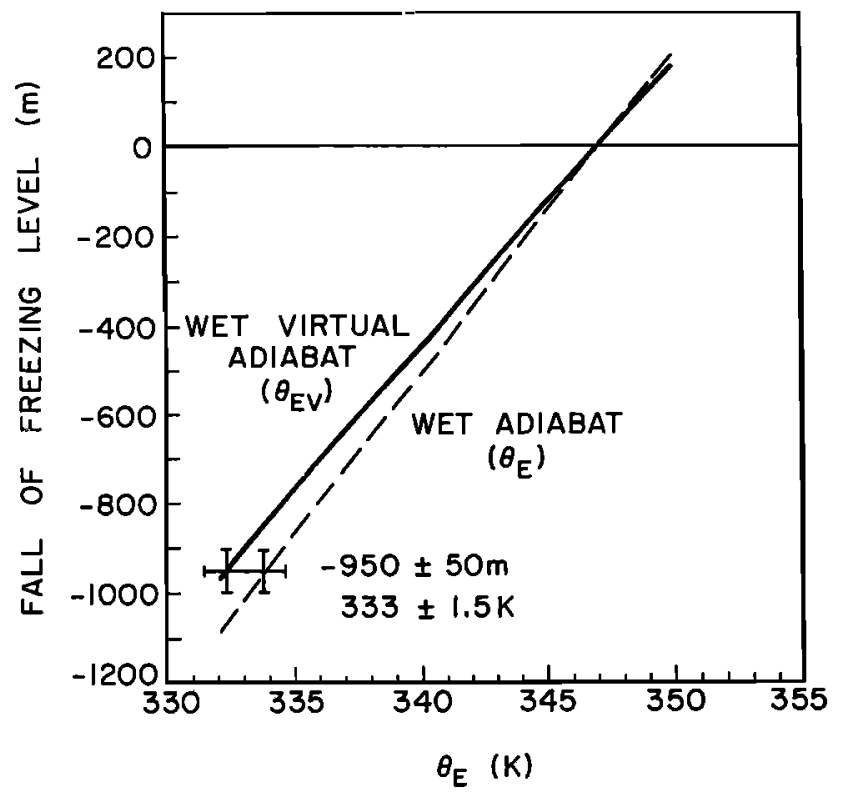

Fig. 2. Fall of freezing level in a wet adiabatic (dashed line) and a wet virtual adiabatic atmosphere (solid line) as a function of low-level equivalent potential temperature, $\theta_{\mathrm{E}}$.

temperature structure follows a wet virtual adiabat up to the freezing level (solid line). The slopes are

$$
\partial \mathrm{z}_{\mathrm{F}} / \partial \theta_{\mathrm{E}}=72 \mathrm{~m} / \mathrm{K}, \partial \mathrm{z}_{\mathrm{F}} / \partial \theta_{\mathrm{EV}}=64 \mathrm{~m} / \mathrm{K}
$$

We assumed $80 \%$ relative humidity (RH) in computing Figure 2, but the dependence on RH is small.

These two idealized models indicate the range of our uncertainty about the tropical temperature structure. The difference between them is small enough, so that we shall simply take an ice age "target value" of $\theta_{\mathrm{E}}=333 \mathrm{~K} \pm 1.5 \mathrm{~K}$ and examine processes that affect low-level $\theta_{\mathrm{E}}$ equilibrium, using a simple model.

\section{Controls on Low-Level $\theta_{\mathrm{E}}$ Equilibrium Over the Tropical Oceans}

We shall use the model of BR89 to discuss the processes which control low-level $\theta_{\mathrm{E}}$ equilibrium over the tropical oceans. This model is a one-dimensional energy balance model for the tropics, which couples the heat and moisture budgets of the convective boundary layer (CBL) and the troposphere. The details of the model are presented in earlier papers. The vertical thermodynamic structure of the CBL is parameterized using a so-called mixing line representation [Betts, 1982, 1985], and above the CBL a moist adiabatic representation is used. Boundary layer cloud fraction is specified, but cloud liquid water and cloud depth are internally computed. A radiation code is used to compute net radiative flux divergence for distinct atmospheric layers (subcloud layer, CBL, and troposphere). Heat and moisture budget equations for these atmospheric layers, together with bulk aerodynamic equations for the surface heat and moisture fluxes, are solved iteratively to find equilibrium solutions for the CBL thermodynamic structure and depth.
The solutions we show here result from varying the boundary conditions of the model. For example, changing SST at constant surface pressure and wind shows the dependence of low-level equilibrium $\theta_{\mathrm{E}}$ on SST. The interactions among the radiation field, the temperature, moisture, and cloud field are complex, but the resulting equilibrium solutions reflect the qualitative discussion in section 1. At equilibrium the surface sensible heat flux, which is determined by the surface wind and sea-air temperature difference, is small $\left(\approx 10 \mathrm{~W} \mathrm{~m}^{-2}\right)$ and closely tied to the net radiative cooling of the subcloud layer. The surface latent heat, which is determined by the surface wind and sea-air mixing ratio difference, balances the drying by subsidence in the CBL. Together, the surface sensible and latent heat fluxes balance the net radiative cooling of the tropics $\left(\approx 150 \mathrm{~W} \mathrm{~m}^{-2}\right)$, plus any small net export of energy out of the tropics. Thus it is the net radiative cooling of the troposphere that primarily determines the surface latent heat flux and at constant wind speed the surface relative humidity (which itself is linked to the height of cloud base). Together, the low-level temperature and humidity give $\theta_{\mathrm{E}}$, so that the model links low-level $\theta_{\mathrm{E}}$ equilibrium to surface boundary conditions and the energy balance of the tropics as a whole.

\subsection{Dependence on SST}

The subcloud layer temperature is quite tightly, coupled to SST; typically, the air over the tropical oceans is about $1^{\circ} \mathrm{C}$ cooler than the ocean because of the strong radiative cooling of the moist subcloud layer. The relative humidity, and hence mixing ratio, however, changes rather slowly with SST through more complex radiative interactions. The dependence of equilibrium $\theta_{\mathrm{E}}$ on sea surface temperature that results is shown in Figure 3. This dependence is large; but at constant surface pressure and wind, it takes a fall in SST of $3.3 \mathrm{~K}$ to drop equilibrium $\theta_{\mathrm{E}}$ to $333 \mathrm{~K}$. This is the puzzle raised by Rind and Peteet [1985], Broecker [1989],

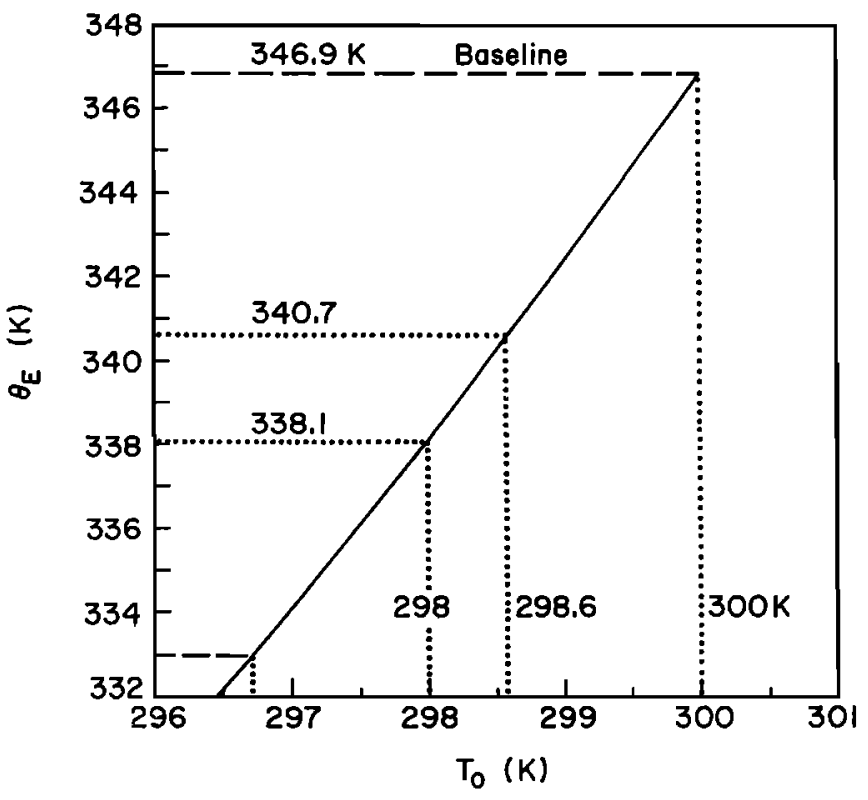

Fig. 3. Dependence of equilibrium low-level $\theta_{\mathrm{E}}$ on sea surface temperature. 
and Rind [1990]. A fall in SST of $1.4 \mathrm{~K}$ drops the $\theta_{\mathrm{E}}$ to only 340.7 $\mathrm{K}$ (the mean value suggested by CLIMAP [1981] for the last glacial maximum) and a $2 \mathrm{~K}$ fall to $338.1 \mathrm{~K}$; these drops of SST alone cannot explain the fall of snowline. The temperature dependence at an SST of $298.5 \mathrm{~K}$ is

$$
\left(\partial \theta_{\mathrm{B}} / \partial \mathrm{T}_{\mathrm{o}}\right)_{\mathrm{Po}_{\mathrm{V}} \mathrm{Y}_{\mathrm{o}}}=4.3
$$

Are there other changes which can also produce falls of $\theta_{\mathrm{E}}$ ?

\subsection{Radiative Feedbacks Associated With Fall of $\mathrm{CO}_{2}$ to $195 \mathrm{ppm}$}

There are small radiative feedbacks in the equilibrium model of BR89 (at a specified SST), associated with the drop of $\mathrm{CO}_{2}$ to $195 \mathrm{ppm}$, and possible changes in the stratospheric equilibrium temperature. These may partly cancel. The drop of $\mathrm{CO}_{2}$ alone drops boundary layer $\theta_{\mathrm{E}}$ by $0.7 \mathrm{~K}$, but this is reduced if the stratosphere warms. Our model [BR89] does not have an interactive stratosphere (or stratospheric chemistry), so for illustration we considered a uniform stratospheric warming of $11 \mathrm{~K}$. The surface fall of $\theta_{\mathrm{E}}$ is then reduced to $0.4^{\circ} \mathrm{C}$. This small drop of $\theta_{\mathrm{E}} 0.4 \mathrm{~K}$ is indicated in Figure 4, which shows the larger surface pressure dependence (section 2.3), but it is clearly uncertain in view of the uncertainties over changes in both stratospheric temperature and moisture near the tropopause. The fall of $\mathrm{CO}_{2}$ concentration is connected to the fall in SST, through the oceanic heat balance, which we are not modeling here, However, given the SSTs [from CLIMAP, 1981], the impact of changing $\mathrm{CO}_{2}$ on the atmospheric $\mathrm{CBL}$ equilibrium is small.

One separate consequence related to a warming of the stratosphere (as well as the fall of low-level $\theta_{\mathrm{B}}$ ) is that the mean tropopause falls from $\approx 133$ mbar to $\approx 180$ mbar. This

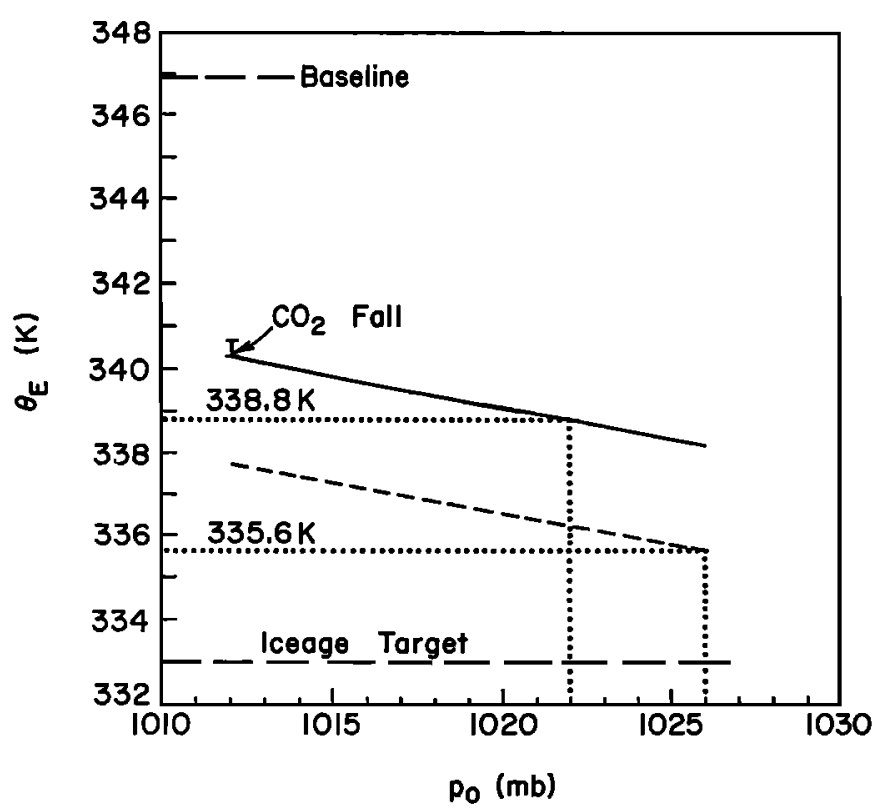

Fig. 4. Dependence of $\theta_{\mathrm{E}}$ on sea surface pressure. could be a significant fall, which might influence the relative humidity and cirrus clouds at outflow levels (which are pootly known at present). We have, however, assumed no change in the relative humidity at the tropopause from an assumed value of $10 \%$.

\subsection{Dependence on Sea Surface Pressure}

A drop of tropical sea level of $\Delta z_{0}=120 \mathrm{~m}$ would increase sea level pressure, $p_{o}$, in the tropics. Essentially, the redistribution of water from the oceans to the ice sheets on the high-latitude continents redistributes the atmosphere so as to reduce the surface pressure over the continents and increase it over the oceans. From the hydrostatic equation the increase in sea level pressure in the tropics is given by

$$
\Delta \mathrm{p}_{0} \approx \rho_{0} g \Delta z_{0}
$$

where $p_{0}$ is the surface density. $\Delta z_{0}=120 \mathrm{~m}$ gives $\Delta p_{0}=14$ mbar. However, the observed fall of sea level at the shoreline may be an overestimate because of the rise of seabeds in compensation for the sinking of continents under the weight of ice, so it is probable that the rise of sea surface pressure is less.

An increase in surface pressure at the same temperature decreases $\theta_{\mathrm{B}}$, as shown schematically in Figure 1. One way of understanding this decrease of $\theta_{E}$ with increasing $p_{0}$ at constant SST is that the air of a fixed temperature cools as it is lifted wet adiabatically, so that it reaches a given pressure at a lower temperature. In the middle troposphere, meanwhile, the freezing level on a given $\theta_{\mathrm{E}}$ adiabat is at a fixed pressure. Figure 4 shows the dependence of $\theta_{\mathrm{E}}$ on $\mathrm{p}_{\mathrm{o}}$ for SSTs of $298.6 \mathrm{~K}$ (solid line) and $298 \mathrm{~K}$ (dashed line), corresponding to the mean and lowest estimates of ice age SST. We have taken current tropical mean $p_{0}$ as 1012 mbar. The value of $p_{0}$ during the ice ages could rise as high as 1026 mbar, but 1022 mbar (a 10-mbar increase) is a reasonable value, allowing for a rise of the seabed of approximately 35 $\mathrm{m}$. The pressure dependence at $298.6 \mathrm{~K}$ is

$$
\partial \theta_{\mathrm{B}} / \partial \mathrm{p}_{\mathrm{o}}=-0.15 \mathrm{~K} / \mathrm{mbar}
$$

This is a significant effect, since it gives a fall of $\theta_{\mathrm{E}}$ of 1.5 $K$ for a 10-mbar rise of sea level pressure. For an ice age SST of $298.6 \mathrm{~K}$ and $\mathrm{p}_{\mathrm{o}}=1022 \mathrm{mbar}$, we then get $\theta_{\mathrm{E}}=338.8$ $K$, which is still much too high to give a $950-\mathrm{m}$ drop of snowline (see Figure 2). For more extreme values of SST = $298 \mathrm{~K}$ and $\mathrm{p}_{\mathrm{o}}=1026 \mathrm{mbar}$, we get $335.6 \mathrm{~K}$ for $\theta_{\mathrm{B}}$, which is getting close. We conclude that unless the tropical ice age SSTs fell at least $2 \mathrm{~K}$, something else must have changed to give a sufficiently low $\theta_{\mathrm{E}}$ in the subcloud layer.

\subsection{Dependence on Surface Wind}

The surface wind speed controls the balance between the surface fluxes and the sea-air differences in temperature and moisture. As wind speed falls, the surface fluxes fall; also, the near-surface air becomes drier and a little cooler as the boundary layer adjusts under the influence of the subsidence and radiation fields [BR89]. It becomes drier as the balance between the reduced evaporation (driven by the 


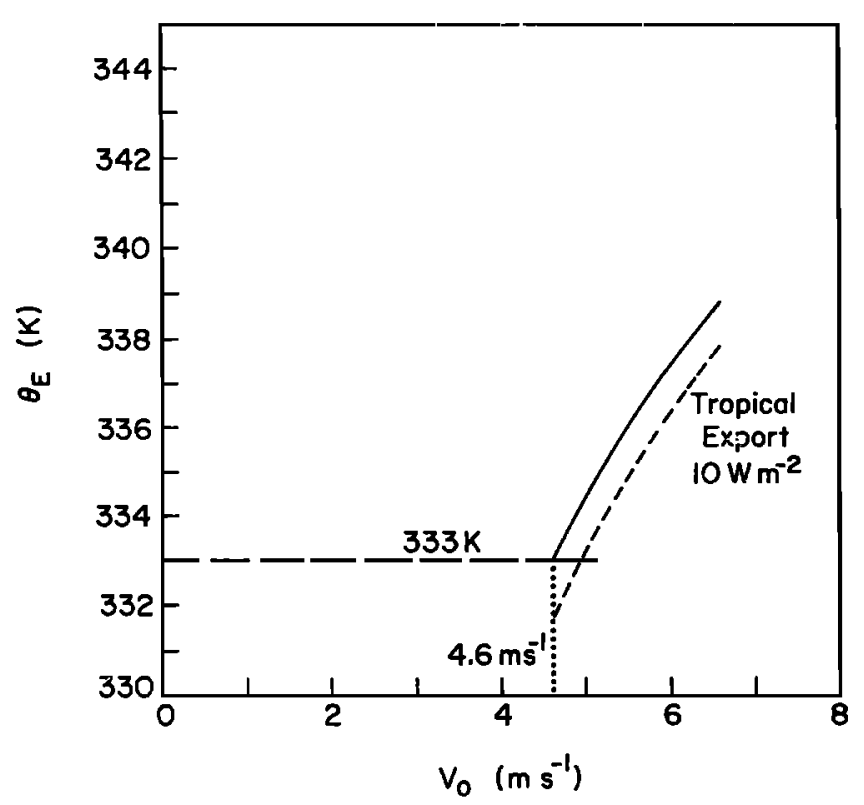

Fig. 5. Dependence of $\theta_{E}$ on surface wind speed.

surface wind) and the subsidence of dry air into the CBL shift to a drier state. It becomes cooler because the surface heat flux drops, while the longwave radiative cooling of the subcloud layer continues.

As a result, there is an important dependence of equilibrium $\theta_{\mathrm{E}}$ on surface wind [BR89]. Figure 5 (solid curve) shows the fall of $\theta_{\mathrm{E}}$ with mean surface wind at a constant SST of $298.6 \mathrm{~K}$ and $\mathrm{p}_{0}$ of $1022 \mathrm{mbar}$. It takes a
$30 \%$ drop in the surface wind from 6.7 to $4.6 \mathrm{~m} \mathrm{~s}^{-1}$ to drop $\theta_{\mathrm{E}}$ to $333 \mathrm{~K}$, which in tum drops the freezing level by $950 \mathrm{~m}$. The slope over this range is

$$
\left(\partial \theta_{\mathrm{B}} / \partial \mathrm{V}_{\mathrm{o}}\right)_{\mathrm{To,po}}=2.5 \mathrm{~K} / \mathrm{m} \mathrm{s}^{-1}
$$

Figure 6 (solid curve) shows the corresponding fall of the relative humidity (RH) of the surface air with wind speed. The fall of $30 \%$ in the surface wind drops RH by $7.4 \%$. This is, however, rather a large fall of surface wind in the tropies, for which we have no satisfactory dynamical explanation. (Equilibrium RH in this model also falls slowly with falling SST $(0.8 \% / K)$ and slightly with increasing $\mathrm{p}_{\mathrm{o}}$ and decreasing $\mathrm{CO}_{2}$; these effects are responsible for the $1.8 \%$ drop of $\mathrm{RH}$ from our baseline case which has an SST of $300 \mathrm{~K}$, and $\mathrm{p}_{0}$ of 1012 mbar.)

In terms of Figure 1 a drop in low-level RH lifts cloud base, giving a deeper dry adiabatic subcloud layer, so that saturation is reached on a cooler wet adiabat. Rind [1990] and Rind and Peteet [1985] point out, however, that a drier troposphere promotes evaporation of snow and ice. This would make the lowering of the snowline more difficult and would require in turn still larger surface changes to produce the observed fall of ice line.

\subsection{Export of Energy From the Tropics to Mid-Latitudes}

The solutions given by BR89 assume energy balance in the tropical atmosphere between the surface fluxes and the net radiative cooling of the troposphere. If this balance changed during the last glacial, so that there was a net

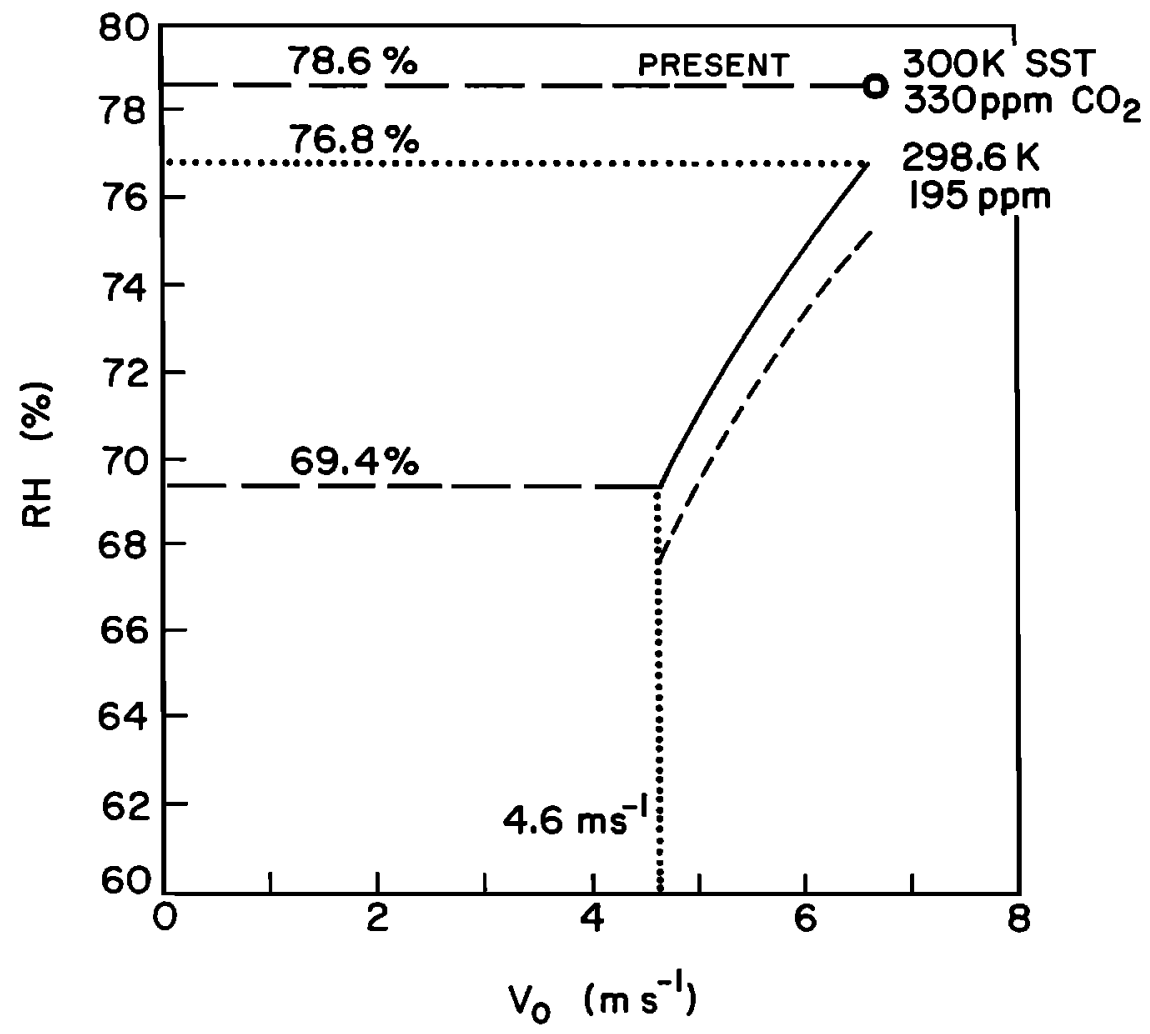

Fig. 6. Dependence of low-level relative humidity on surface 
atmospheric export from the tropics to the extratropics, then this would enhance the tropical surface fluxes and drop CBL $\theta_{\mathrm{E}^{-}}$The physical mechanism by which this is achieved is a small increase in the mean subsidence in the tropics, which shifts the CBL to a drier equilibrium state and produces an increase in the surface evaporation at constant surface temperature and wind speed. The lower dashed curves in Figures 5 and 6 show the effect of a $10 \mathrm{~W} \mathrm{~m}^{-2}$ atmospheric export of energy from the tropics. This is sufficient to drop low-level $\theta_{\mathrm{E}}$ by $1.1 \mathrm{~K}$. For comparison, in our model without this energy export, the total surface sensible and latent heat fluxes fall from a current baseline value of 158 to $145 \mathrm{~W} \mathrm{~m}^{-2}$ for the ice age conditions. An increase in the evaporation of $10 \mathrm{~W} \mathrm{~m}^{-2}$ is sufficient to drop sea level by $120 \mathrm{~m}$ in 1100 years. Such an increase might be necessary to provide the net atmospheric transport of water to the northern ice sheets. Although this has a longer time scale of the order of 10,000 years, the atmospheric transport processes are unlikely to be $100 \%$ efficient.

\section{Conclusion}

A fall of tropical SSTs by $2 \mathrm{~K}$ during the last iceage and an increase of tropical sea surface pressure by $14 \mathrm{mbar}$ would account for about an $800-\mathrm{m}$ fall of freezing level. However, a $1.4 \mathrm{~K}$ mean fall of tropical SST [CLIMAP, 1981] and a more probable 10-mbar increase of sea surface pressure drops the freezing level only about $550 \mathrm{~m}$. This is far short of the $950 \pm 50 \mathrm{~m}$ observed. One possibility is that in addition the mean surface wind fell in the tropics, so that the low-level equilibrium relative humidity (and corresponding $\theta_{\mathrm{E}}$ ) also fell. The solutions here show that a 30\% drop in mean surface wind to about $4.6 \mathrm{~m} \mathrm{~s}^{-1}$ drops the $\mathrm{RH}$ a further $7 \%$, so that the total fall of freezing level is $950 \mathrm{~m}$, even with an SST drop of only $1.4 \mathrm{~K}$. An alternative process, which in our model acts to reduce $\theta_{\mathrm{E}}$ and $\mathrm{RH}$ in a very similar way, is a net atmospheric export of energy from the tropics to higher latitudes, associated with a continued high evaporation in the tropics (but not increased precipitation). This could produce some of the fall of $\theta_{\mathrm{E}}$, but probably some fall of wind speed would also be needed. There is evidence [Rind and Peteet, 1985] that the tropics were more arid during the last glacial maximum. However, a drier tropics with probably less precipitation would tend to reduce the fall of the ice line. Thus if the CLIMAP [1981] reconstructions of the tropical SSTs are correct, the puzzle presented by Rind and Peteet [1985] still remains. It would require a remarkable change in the mean structure of the tropical boundary layer to explain the 950-m drop of freezing level.
Acknowledgments. My interest in this was sparked by correspondence between W. Broecker and M. E. MacIntyre. I am grateful for support from the National Science Foundation under grant ATM90-01960, the NASA Goddard Space Flight Center under contract NAS5-30524, and also for discussions with $\mathrm{K}$. Emanuel and the comments of a reviewer.

\section{References}

Betts, A. K., Saturation point analysis of moist convective overturning, J. Atmos. Sci., 39, 1484-1505, 1982.

Betts, A. K., Mixing line analysis of clouds and cloudy boundary layers, J. Atmos. Sci., 42, 2751-2763, 1985.

Betts, A. K., and W. L. Ridgway, Climatic equilibrium of the atmospheric convective boundary layer over a tropical ocean, J. Atmos. Sci. 46, 2621-2641, 1989.

Betts, A. K., and J. Bartlo, The density temperature and the dry and wet virtual adiabats, Mon. Weather Rev., 119 , 169-175, 1991.

Broeker, W., Summary of lapse rate symposium, paper presented at the Lamont Doherty Geol. Observ., Palisades, NY, October 5, 1989.

Climate: Long-Range Investigation, Mapping, and Prediction (CLIMAP) Project Members, Seasonal reconstruction of the earth's surface at the last glacial maximum, Geol. Soc. Am. Map and Chart Ser. 36, 1981.

Riehl, H. Climate and Weather in the Tropics, 611 pp., Academic, San Diego, Calif., 1979.

Rind, D., and D. Peteet, Terrestrial conditions at the last glacial maximum and CLIMAP sea-surface temperature estimates: Are they consistent?, Quat. Res. 24, 1-22, 1985.

Rind, D., The doubled $\mathrm{CO}_{2}$ climate: Impact of the sea surface temperature gradient., J. Atmos. Sci. 44 , 3235-3268, 1987.

Rind, D., Puzzles from the tropics, Nature, $346,317-318$, 1990.

Xu, K.M., and K.A. Emanuel, Is the tropical atmosphere conditionally unstable?, Mon. Weather. Rev. 117, 1471$1479,1989$.

A. K. Betts, Atmospheric Research, RD 2, Box 3300, Middlebury, VT 05753.

W. Ridgway, Applied Research Corporation, Landover, MD 20785.

(Received April 3, 1991; revised November 15, 1991; accepted November 18, 1991.) 